\title{
Endothelial preconditioning by transient oxidative stress reduces inflammatory responses of cultured endothelial cells to TNF- $\alpha$
}

\author{
STEFAN ZAHLER, ${ }^{1}$ CHRISTIAN KUPATT, AND BERNHARD F. BECKER \\ Department of Physiology, Ludwig-Maximilians-University, Munich, Germany
}

\begin{abstract}
Brief episodes of ischemia can render an organ resistant to subsequent severe ischemia. This 'ischemic preconditioning' is ascribed to various mechanisms, including oxidative stress. We investigated whether preconditioning exists on an endothelial level. Human umbilical vein endothelial cells (HUVECs) were transiently confronted with

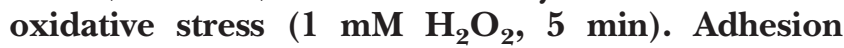
molecules ICAM-1 and E-selectin and release of cytokines IL-6 and IL-8 to subsequent stimulation with TNF- $\alpha(2.5 \mathrm{ng} / \mathrm{ml}, 4 \mathrm{~h})$ were measured (flow cytometry and immunoassay), as were nuclear translocation of the transcription factor NFKB (Western blotting, confocal microscopy) and redox status of HUVECs (quantification of glutathione by HPLC). TNF- $\alpha$ elevated IL-6 in the cell supernatant from $8.8 \pm 1$ to $41 \pm 3 \mathrm{pg} / \mathrm{ml}$ and IL-8 from $0.5 \pm 0.03$ to $3 \pm 0.2 \mathrm{ng} / \mathrm{ml}$. ICAM-1 was increased threefold and E-selectin rose eightfold. Oxidative stress (decrease of glutathione by $50 \%$ ) reduced post-TNF- $\alpha$ levels of IL-6 to $14 \pm 3$ and IL-8 to $1 \pm 0.2$; the rise of ICAM-1 was completely blocked and E-selectin was only doubled. The anti-inflammatory effects of preconditioning via oxidative stress were paralleled by reduction of the translocation of NFKB on stimulation with TNF- $\alpha$, and antagonized by the intracellular radical scavenger $\mathrm{N}$-acetylcysteine. 'Anti-inflammatory preconditioning' of endothelial cells by oxidative stress may account for the inhibitory effects of preconditioning on leukocyte adhesion in vivo.Zahler, S., Kupatt, C., Becker, B. F. Endothelial preconditioning by transient oxidative stress reduces inflammatory responses of cultured endothelial cells to TNF- $\alpha$. FASEB J. 14, 555-564 (2000)
\end{abstract}

Key Words: cytokine $\cdot$ adhesion molecule $\cdot N F \mathrm{k} B \cdot$ glutathione

REPERFUSION OF PREviously ischemic tissue paradoxically leads to an increase of tissue damage and dysfunction $(1,2)$. In the light of yearly rising numbers of cardiac interventions invoking transient ischemia (PTCA, thrombolysis, coronary bypass grafting, valve replacement, transplantation, CPB), the incidence of reperfusion, and thus reperfusion injury, gains ever-increasing relevance. Reperfusion is restricted mostly to clinical settings, and therefore is a planned intervention. Accordingly, awareness has grown that patients might benefit substantially from a deeper knowledge of the mechanisms underlying reperfusion injury, since this should lead to subsequent development of protective strategies.

To date, the most powerful tool for experimentally reducing infarct size after ischemia and reperfusion is the so-called 'ischemic preconditioning'. This phenomenon was first described by Murry and co-workers (3), who have shown that brief, transient episodes of ischemia 'precondition' myocardium to become more resistant against a subsequent severe ischemic insult. Since then the research interest in this effect has grown constantly, and a variety of potential mechanisms have been proposed: adrenergic stimulation (4), activation of adenosine receptors (5), opening of $\mathrm{K}_{\mathrm{ATP}}$ channels (6), induction of heat shock proteins (7), and induction of oxidative stress (8), just to mention those that are established best. However, the effector cells of preconditioning are only poorly defined. Apart from parenchymal cells, especially cells of the vascular wall seem of interest, because reperfusion injury is, at least in part, a misguided inflammatory response (9). In this sense, ischemic preconditioning has previously been shown to reduce adhesion of leukocytes to postischemically reperfused vessels (10).

The proinflammatory mediator tumor necrosis factor $\alpha(\mathrm{TNF}-\alpha)$ plays a key role during ischemia and reperfusion $(11,12)$, modulating cell adhesion molecules, cytokines, and chemokines. We have therefore investigated whether the responses of endothelial cells to TNF- $\alpha$ can be modulated by a protocol mimicking ischemic preconditioning. The stimulus chosen was that of brief redox stress imposed by transient application of hydrogen peroxide. Oxidative stress has been shown to occur during preconditioning (13) and to be mandatory for the

\footnotetext{
${ }^{1}$ Correspondence: Institute of Physiology, Schillerstr. 44, 80336 Munich, Germany. E-mail: s.zahler@lrz.unimuenchen.de
} 
success of preconditioning in some models $(14,15)$. This also seemed of broader interest because the modulation of cellular redox status has recently turned out to be a major signal for inflammatory reactions $(16,17)$.

Preconditioning at first seemed to be a temporally limited phenomenon, being acutely effective only within periods of less than $1 \mathrm{~h}$. Recently, however, a 'second window of protection' has been identified, occurring some $24 \mathrm{~h}$ after the preconditioning period $(7,18)$. Thus, we also tested whether an antiinflammatory effect still pertains after a $24 \mathrm{~h}$ lag phase between preconditioning and inflammatory stimulus still allows.

The inflammatory parameters measured in cultures of human umbilical vein endothelium were the expression of the adhesion molecules ICAM-1, Eselectin, and P-selectin and secretion of the cytokines interleukin 6 (IL-6) and IL-8. The redox status of the cells was monitored by separate measurement of the intracellular concentration of reduced glutathione (GSH). Application of the GSH precursor N-acetylcysteine served to manipulate the intracellular redox status. Potential effects of the experimental protocols on cell apoptosis and necrosis were investigated by measurement of annexin- $\mathrm{V}$ binding and of lactate dehydrogenase $(\mathrm{LDH})$ release. Involvement of the transcription factor NFкB (nuclear factor $\kappa \mathrm{B}$ ), which has been shown to be both redox sensitive (19) and to participate in the regulation of the inflammatory parameters listed above, was also studied.

\section{MATERIALS AND METHODS}

\section{Endothelial cell culture}

Human umbilical vein endothelial cells (HUVECs) were isolated from fresh umbilical cords according to the method of Jaffe (20). Briefly, the umbilical vein was cannulated, rinsed with phosphate buffer, and filled with collagenase A (1 $\mathrm{mg} / \mathrm{ml}$ ) for $5 \mathrm{~min}$ at $37^{\circ} \mathrm{C}$. Endothelial cells were eluted with medium 199, centrifuged, washed, pelleted again, and then seeded with endothelial cell growth medium (Promocell, Heidelberg, Germany) into T 25 culture flasks. After reaching confluence, the primary cultures were detached from the flask with trypsin and transferred into 24-well culture dishes coated with collagen A (Biochrom, Berlin, Germany). Experiments were performed 2 days after the cells had reattained confluence.

\section{Flow cytometry}

The expression levels of the adhesion molecules ICAM-1, E-selectin, and P-selectin on HUVECs, as well as the binding of annexin- $V$ to these cells, were quantified by flow cytometry. Cell monolayers were washed with phosphate-buffered saline (PBS) without calcium and incubated with a trypsin solution (in the case of P-selectin, a collagenase solution, P-selectin being rapidly activated in response to trypsin) until the cells were detached from the culture dish. The cells were treated with CellFix (Becton Dickinson, Heidelberg, Germany) and passed through a nylon net $(70 \mu \mathrm{m}$ mesh). The cells were pelleted by centrifugation, resuspended in CellWash (Becton Dickinson), labeled with the respective antibodies, washed, and measured on a FACScan flow cytometer (Becton Dickinson). The antibodies MCA675PE, MCA883F, and MCA796PE (all Serotec, Kidlington, U.K.) were used to detect ICAM-1, E-selectin, and P-selectin, respectively. Data analysis was performed with Lysis II software (Becton Dickinson). The median of the specific fluorescence intensity was used as a marker for expression of the respective epitope; nonspecific fluorescence was detected by using isotype-matched nonbinding antibodies (Serotec) and subtracted. Binding of annexin-V to HUVECs was determined with an apoptosis detection kit (PharMingen, Heidelberg, Germany) containing FITC-labeled annexin-V, propidium iodide, and a calciumrich binding buffer. The staining protocol complied with the manufacturer's instructions. Median fluorescence intensity of FITC on propidium iodide negative (i.e., living) cells was used as a measure of apoptosis.

\section{Photometric tests}

Levels of the cytokines IL-6 and IL- 8 were determined in cell culture supernatants with commercially available ELISAs (Endogen, Woburn, Mass.). To determine IL-8, the samples were diluted 1:100. Sample aliquots of $50 \mu \mathrm{l}$ were used per well of the test plate in all cases; staining and measurement were performed as proscribed by the manufacturer. Briefly, the ELISA plates were incubated with the standards or samples for $60 \mathrm{~min}$. Unbound cytokine was removed by washing three times, and a second antibody (labeled enzymatically for photometric detection) was added. After further incubation and removal of unbound antibody by washing, the plates were analyzed photometrically with a microplate reader (Dynatech, Guernsey, U.K.) at $450 \mathrm{~nm}$. As an indicator of cellular death, release of the enzyme $\mathrm{LDH}$ into the supernatant was also measured photometrically at $490 \mathrm{~nm}$ (CytoTox96 assay, Promega, Mannheim, Germany).

\section{Measurement of GSH}

After removal of medium, HUVECs were lysed with 400 $\mu \mathrm{l} /$ well of a stopping solution (64 mM N-ethylmaleimide in $0.5 \mathrm{M}$ perchloric acid) to prevent autoxidation of GSH. Concentrations in the lysate are termed intracellular, no attempt having been made to correct this to the real intracellular volume. GSH was analyzed directly by high-performance liquid chromatography (HPLC) as the NEM adduct at a wavelength of $202 \mathrm{~nm}$. Two hundred microliters of the respective sample were applied to a $5 \mu \mathrm{m} \mathrm{C}-18$ nucleosil column (Macherey and Nagel, Düren, Germany); $25 \mathrm{mM}$ $\mathrm{NH}_{4} \mathrm{H}_{2} \mathrm{PO}_{4}$ containing $1.2 \%$ methanol served as eluent. At a flow of $1 \mathrm{ml} / \mathrm{min}$, the retention time was $\sim 13 \mathrm{~min}$.

\section{Western blot analysis}

HUVECs were lysed in a reducing Triton lysis buffer (Tris 1 $\mathrm{mM}$, NaCl $50 \mathrm{mM}$, Triton $1 \times$, sodium vanadate $5 \mathrm{mM}$, NaF 50 $\mathrm{mM}$, Na pyrophosphate $30 \mathrm{mM}$, DTT $1 \mathrm{mM}$, PMSF $1 \mathrm{mM}$, leupeptin $10 \mu \mathrm{M}$, pepstatin $10 \mu \mathrm{M})$. Nuclear and cytosolic fractions were separated by centrifugation $(10,000 \mathrm{~g}$ for $5 \mathrm{~s})$, the membrane fractions were removed by 15 min centrifugation at $10,000 \mathrm{~g}\left(4^{\circ} \mathrm{C}\right)$. The protein concentrations of the lysates (nuclear and cytosolic) were determined with a detergent compatible assay (BCA, Pierce, Rockford, Ill.). Aliquots $(40 \mu \mathrm{g})$ of protein were separated on a $12 \%$ polyacylamide gel, transferred to a nitrocellulose membrane (Hybond-en- 
hanced chemiluminescence, Amersham, Braunschweig, Germany), blocked with buffer containing $5 \%$ nonfat dry milk, and incubated with $2 \mu \mathrm{g} / \mathrm{ml}$ of primary antibody (anti-p65

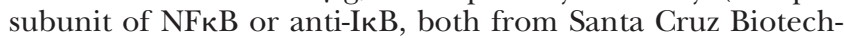
nology, Santa Cruz, Calif.). After washing four times with buffer containing $1 \%$ nonfat dry milk, the membranes were exposed to $0.2 \mu \mathrm{g} / \mathrm{ml}$ of secondary antibody, labeled with horseradish peroxidase (Santa Cruz). The membranes were then incubated with an enhanced chemiluminescence kit (Pierce) for $1 \mathrm{~min}$ and exposed to an X-ray film. The films were analyzed with a video system (GelDoc 1000, Bio-Rad, Hercules, Calif.) and optical density of the bands was calculated with MolecularAnalyst software (Bio-Rad). Due to considerable interindividual variability, values are expressed as percentual changes vs. controls $(100 \%)$. Analogous experiments were performed with the cytoplasmatic fractions to control the purity of the nuclear and cytoplasma preparation, respectively.

\section{Confocal microscopy}

To determine the subcellular localization of NFкB, stimulated HUVECs were fixed with buffered formaldehyde (3\%) and subsequently permeabilized by submersion in $0.2 \%$ Triton X-100 in PBS for $2 \mathrm{~min}$. The samples were rinsed three times with PBS, blocked with $0.2 \%$ BSA in PBS for $15 \mathrm{~min}$, and incubated with the primary antibody against p65 (Santa Cruz) for $45 \mathrm{~min}$. After four washings, the secondary antibody (FITC labeled, Santa Cruz) was added and samples were incubated for $30 \mathrm{~min}$ at room temperature. After four final washing steps, the cells were covered with mounting medium (Sigma, Eching, Germany) and a coverslip before inspection with a confocal microscope (LSM 410 Invert, Zeiss, Jena, Germany).

\section{Experimental protocols}

Flow charts of the experimental protocols $A-C$ are depicted in Fig. 1. In preconditioning experiments, medium was removed from confluent HUVECs and replaced by PBS containing 1 $\mathrm{mM} \mathrm{H} \mathrm{H}_{2} \mathrm{O}_{2}$ for $5 \mathrm{~min}$ at $37^{\circ} \mathrm{C}$. Afterward, the supernatant was removed and the cells were covered with standard medium again. The cells were then incubated with TNF- $\alpha(2.5 \mathrm{ng} / \mathrm{ml})$ for $4 \mathrm{~h}$, after which supernatant was sampled for measurement of IL-6, IL-8, and LDH. Cells were detached and treated for flow cytometric analysis of ICAM-1, E-selectin, P-selectin, and annexin-V binding (Fig. 1A). Time matched controls were treated with neither $\mathrm{H}_{2} \mathrm{O}_{2}$ nor TNF- $\alpha$. Further experimental groups consisted of cells that had been treated with $\mathrm{H}_{2} \mathrm{O}_{2}(5 \mathrm{~min})$ or $\mathrm{TNF}-\alpha(4 \mathrm{~h})$ alone. In protocol $B$, these experiments were repeated in cells that had been pretreated with the intracellular radical scavenger $\mathrm{N}$-acetylcysteine (NAC, $1 \mathrm{mM}$ ) for $30 \mathrm{~min}$. After this incubation, the cells were washed to remove all extracellular NAC and then subjected to the aforementioned procedures. Some of the experiments of protocols $A$ and $B$ were terminated $5 \mathrm{~min}$ or $30 \mathrm{~min}$ after the $\mathrm{H}_{2} \mathrm{O}_{2}$ stimulus to allow for determination of intracellular GSH or for analysis of the subcellular localization of NFKB or IкB (Fig. 1). To investigate whether transient redox stress causes a second window of protection against stimulation with TNF- $\alpha$, a $24 \mathrm{~h}$ interval was allowed between stimulation with $\mathrm{H}_{2} \mathrm{O}_{2}$ and TNF- $\alpha$. During this time the cells were kept in the incubator with standard medium. Afterward, TNF- $\alpha$ was given for $4 \mathrm{~h}$ and the experiments were continued as described above (Fig. 1, protocol $C$ ).

\section{Statistical procedures}

Data are usually expressed as mean $\pm \mathrm{sE}$; $n$ values are shown in Results. Statistical analysis was performed with 2-way ANOVA. One factor for group comparisons was treatment with TNF- $\alpha$ or not; the other factor was treatment with $\mathrm{H}_{2} \mathrm{O}_{2}$ or not. Pairwise multiple comparison tests were carried out using the Student-Newman-Keuls test. Differences between groups were considered significant for $P \leq 0.05$.

\section{RESULTS}

\section{Expression of adhesion molecules}

HUVECs showed constitutive expression of ICAM-1 on a low level (mean fluorescence intensity $3.9 \pm 0.3$ arbitrary units, Fig. 2). Short incubation with $\mathrm{H}_{2} \mathrm{O}_{2}$ ( $1 \mathrm{mM}$ for $5 \mathrm{~min}$ ) did not alter ICAM-1 expression within $4 \mathrm{~h}$. In contrast, stimulation with TNF- $\alpha$ (2.5 $\mathrm{ng} / \mathrm{ml}$ for $4 \mathrm{~h}$ ) elevated ICAM-1 threefold

\section{Protocol}

A
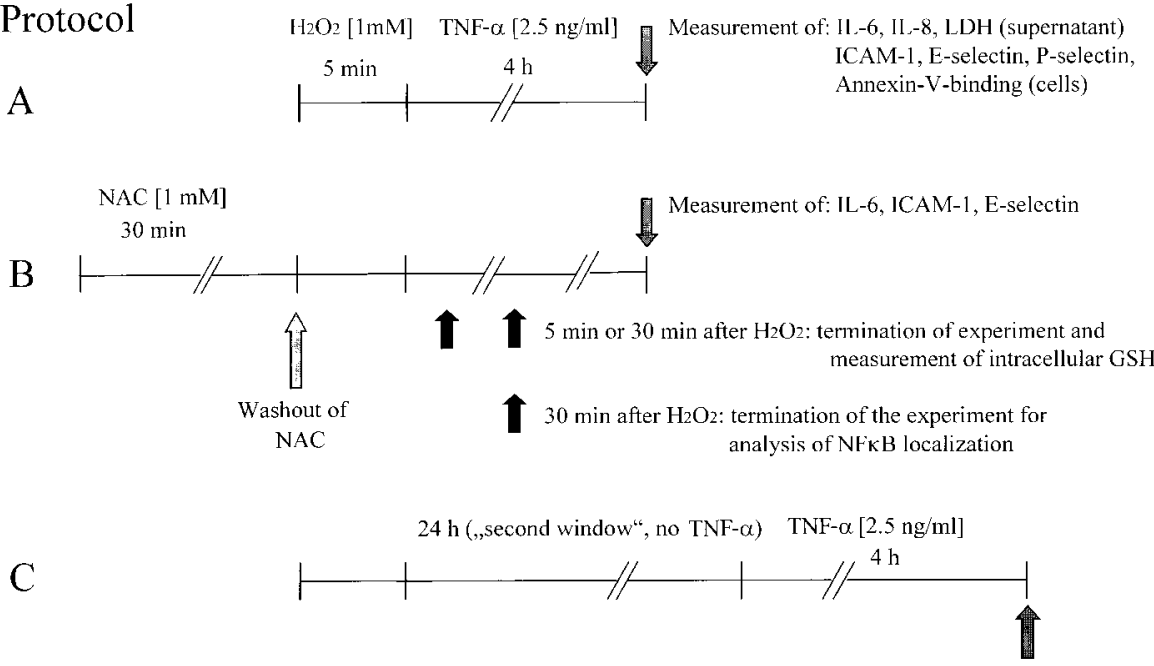

Measurement of: IL-6, IL-8, LDH, ICAM-1,

E-selectin, Annexin-V-binding
Figure 1. Flow diagram of the various experimental protocols. A) Standard protocol, $B$ ) preincubation with $\mathrm{N}$-acetylcysteine (NAC), C) $24 \mathrm{~h}$ latency between $\mathrm{H}_{2} \mathrm{O}_{2}$ and TNF- $\alpha$ treatment (second window of protection). 
ICAM-1

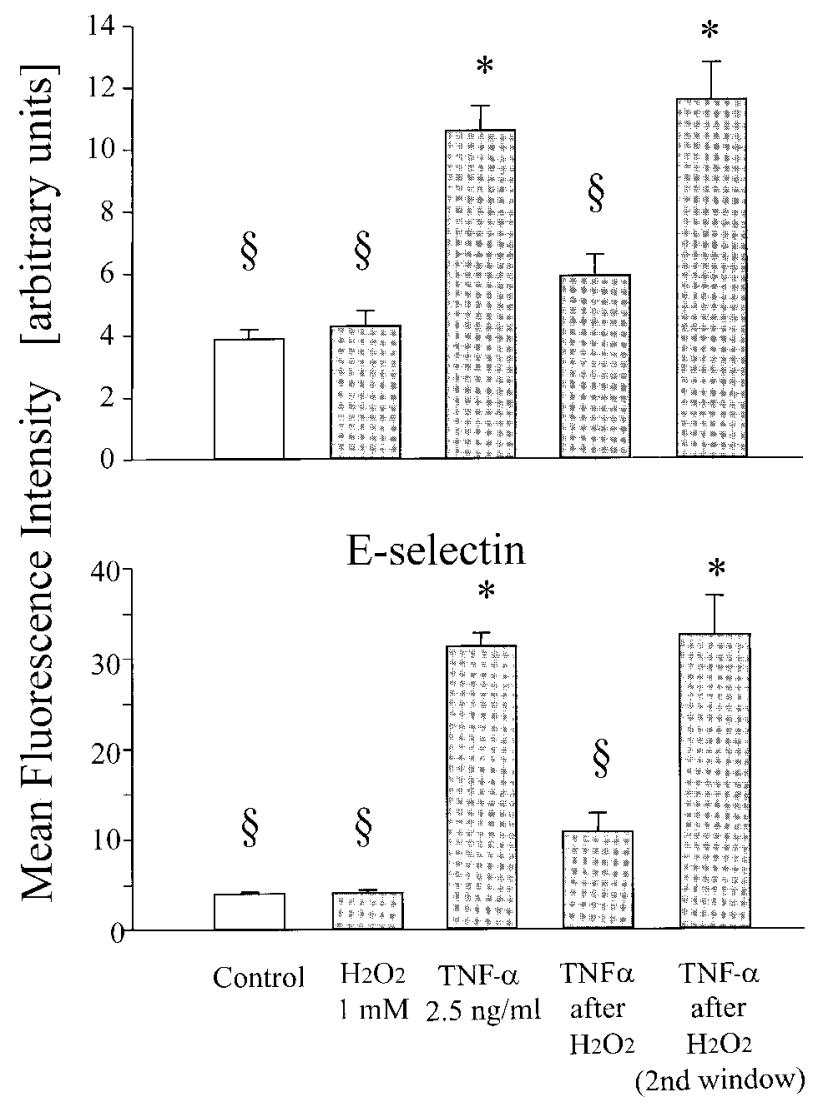

Figure 2. Expression of the adhesion molecules ICAM-1 (upper panel) and E-selectin (lower panel) on HUVECs, measured by flow cytometry. Controls: $n=19$ different cultures. $\mathrm{H}_{2} \mathrm{O}_{2}: n=14$, TNF- $\alpha: n=31$, TNF- $\alpha$ after $\mathrm{H}_{2} \mathrm{O}_{2}: n=19$, 2nd window: $n=6$. Means $\pm \mathrm{SE}$; *significantly different vs. control, §significantly different vs. TNF $\alpha, P \leq 0.05$.

(10.6 \pm 0.8 , Fig. 2). Pretreatment with $\mathrm{H}_{2} \mathrm{O}_{2}$ strongly

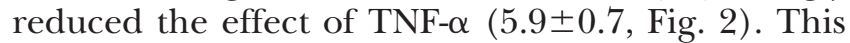
action was not observed when stimulation with TNF- $\alpha$ occurred $24 \mathrm{~h}$ after treatment with $\mathrm{H}_{2} \mathrm{O}_{2}$ (Fig. 2). Preincubation of the HUVECs with the intracellular radical scavenger NAC $(1 \mathrm{mM}, 30 \mathrm{~min})$ did not alter constitutive ICAM-1 levels or the response to TNF- $\alpha(4.0 \pm 0.7$ and $12.9 \pm 1.1$, respectively, Fig. 4), whereas the inhibitory effect of $\mathrm{H}_{2} \mathrm{O}_{2}$ on TNF- $\alpha$ dependent ICAM-1 expression was abolished $(9.9 \pm 2.5)$.

Expression of the adhesion molecule E-selectin was regulated in an analogous way. Basal expression (4.0 \pm 0.2 , Fig. 2) was unaltered by $\mathrm{H}_{2} \mathrm{O}_{2}$ alone, whereas TNF- $\alpha$ led to an eightfold increase (31 \pm 3 , Fig. 2). This was dramatically infringed by pretreatment with $\mathrm{H}_{2} \mathrm{O}_{2}(10.8 \pm 2$, Fig. 2). Again, there was no second window after $24 \mathrm{~h}$. NAC did not influence the constitutive E-selectin level $(3.5 \pm 0.3)$ or the effect of TNF- $\alpha$ (32.2 \pm 4.8 , Fig. 4). However, the blocking action of $\mathrm{H}_{2} \mathrm{O}_{2}$ was nearly neutralized by NAC (27.5 \pm 3.7$)$.

The presence of P-selectin behaved in a different way: $\mathrm{H}_{2} \mathrm{O}_{2}$, as well as TNF- $\alpha$ or the combination of both stimuli, elevated basal expression from $4.15 \pm$ 0.13 to $5.38 \pm 0.17,5.14 \pm 0.16$, and $5.88 \pm 0.34$, respectively (Table $\mathbf{1}$ ).

\section{Secretion of cytokines}

Cytokines IL-6 and IL- 8 were both constitutively secreted by HUVECs $(8.9 \pm 1.4$ and $450.4 \pm 36 \mathrm{pg} / \mathrm{ml}$, respectively, Fig. 3). $\mathrm{H}_{2} \mathrm{O}_{2}$ alone caused no changes, whereas TNF- $\alpha$ increased the levels of both cytokines substantially to $40.6 \pm 3.3$ for IL-6 and $2960 \pm 192$ $\mathrm{pg} / \mathrm{ml}$ for IL-8 (Fig. 3). These increases were mitigated by application of $\mathrm{H}_{2} \mathrm{O}_{2}$ prior to TNF- $\alpha$ $(14.4 \pm 2.9$ and $1015 \pm 159 \mathrm{pg} / \mathrm{ml}$, resp., not significant vs. control). When TNF- $\alpha$ was applied with a latency of $24 \mathrm{~h}$ after $\mathrm{H}_{2} \mathrm{O}_{2}$ treatment, this inhibitory effect was only marginal and not significant. Preincubation of the cells with NAC decreased constitutive levels of IL-6 release to $3.2 \pm 1.5 \mathrm{pg} / \mathrm{ml}$, but did not affect the increase mediated by TNF- $\alpha(45.6 \pm 2 \mathrm{pg} /$ ml, Fig. 4). The loss of efficacy of TNF- $\alpha$ after $\mathrm{H}_{2} \mathrm{O}_{2}$ was less pronounced under the influence of NAC ( $25 \pm 4 \mathrm{pg} / \mathrm{ml}$, Fig. 4). IL-8 release was not determined in this series.

\section{Levels of GSH in cell lysates}

Intracellular GSH levels, as determined in cell lysates, are illustrated in Fig. 5. Control levels of GSH in HUVEC lysates were $0.48 \pm 0.03 \mu \mathrm{M}$. This value was reduced by half $(0.25 \pm 0.01 \mu \mathrm{M}) 5 \mathrm{~min}$ after stimulation with $\mathrm{H}_{2} \mathrm{O}_{2}$, whereas TNF- $\alpha$ (5 min) had no effect $(0.53 \pm 0.03 \mu \mathrm{M})$. The loss of GSH due to $\mathrm{H}_{2} \mathrm{O}_{2}$ was not aggravated or reduced by additional application of TNF- $\alpha(0.26 \pm 0.03 \mu \mathrm{M})$. Pretreatment with NAC doubled the constitutive GSH level $(0.85 \pm 0.04 \mu \mathrm{M})$. Though $\mathrm{H}_{2} \mathrm{O}_{2}$ also caused a reduction of GSH in this protocol $(0,44 \pm 0.03 \mu \mathrm{M})$, the resulting concentration did not differ from the resting level in untreated cells. Again, TNF- $\alpha$ had no effect, either alone $(0.75 \pm 0.03 \mu \mathrm{M})$ or in combination with $\mathrm{H}_{2} \mathrm{O}_{2}(0.38 \pm 0.02 \mu \mathrm{M})$. At $30 \mathrm{~min}$ after stimulation, GSH levels were still slightly reduced in all the $\mathrm{H}_{2} \mathrm{O}_{2}$-treated cells (Fig. 5), but this decrease

TABLE 1. Flow cytometric evaluation of P-selectin expression on HUVECs 4 h after stimulation ${ }^{a}$

\begin{tabular}{lc}
\hline \hline Experimental condition & $\begin{array}{c}\text { P-selectin specific fluorescence } \\
\text { (arbitrary units) }\end{array}$ \\
\hline Control & $4.15 \pm 0.13$ \\
$\mathrm{H}_{2} \mathrm{O}_{2}(1 \mathrm{mM}, 5 \mathrm{~min})$ & $5.39 \pm 0.17^{*}$ \\
$\mathrm{TNF} \alpha(2.5 \mathrm{ng} / \mathrm{ml})$ & $5.14 \pm 0.16^{*}$ \\
$\mathrm{TNF} \alpha$ after $\mathrm{H}_{2} \mathrm{O}_{2}$ & $5.88 \pm 0.34^{*}$ \\
\hline
\end{tabular}

${ }^{a} n=6$ for all conditions; * significant vs. control $(P \leq 0.05)$, means \pm SD. 


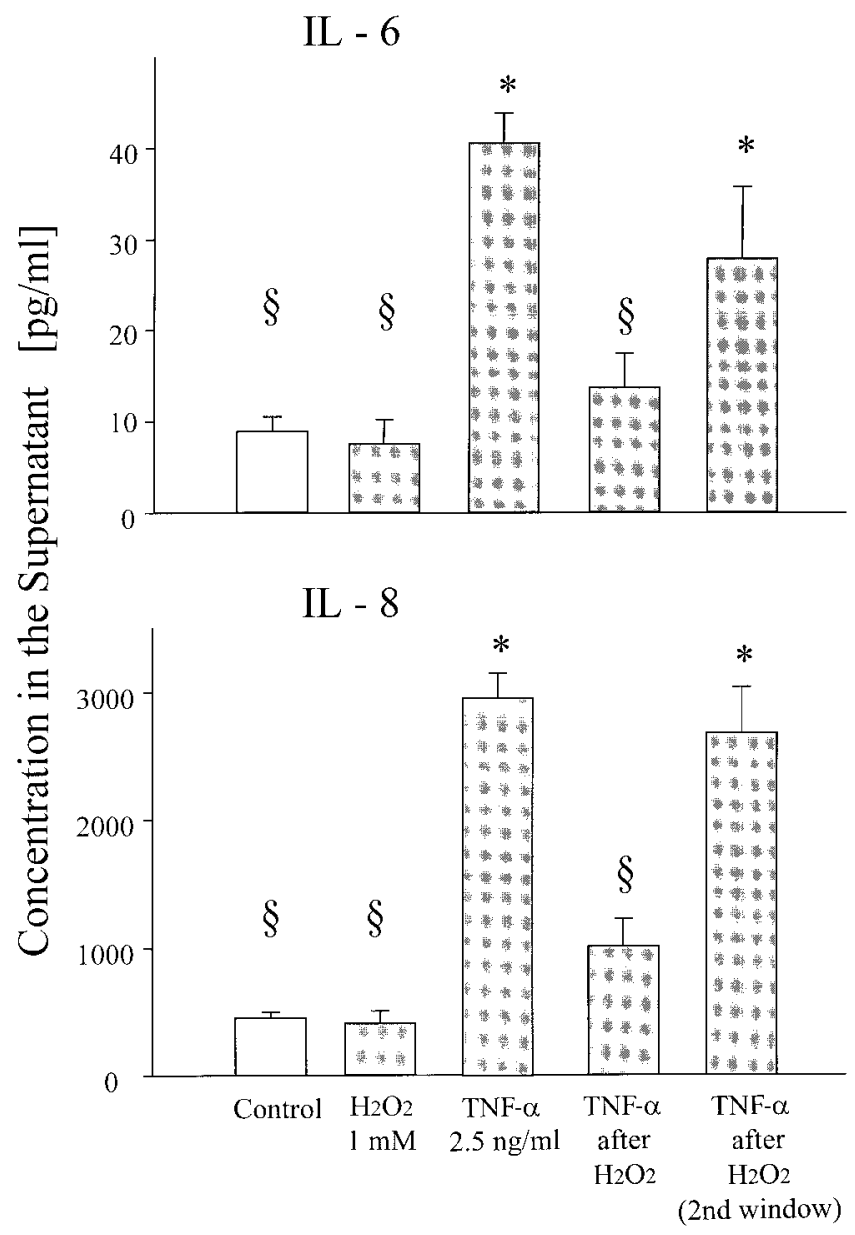

Figure 3. Concentrations of the cytokines IL-6 (upper panel) and IL-8 (lower panel) in the supernatant of HUVECs were measured by ELISA. Controls: $n=19$ cultures, $\mathrm{H}_{2} \mathrm{O}_{2}: n=14$, TNF- $\alpha: n=31$, TNF- $\alpha$ after $\mathrm{H}_{2} \mathrm{O}_{2}: n=19$, 2nd window: $n=6$. Means $\pm \mathrm{SE}$; *significantly different from control, §significantly different vs. TNF $\alpha, P \leq 0.05$.

did not reach statistical significance vs. controls and the TNF- $\alpha$ group.

\section{Quantification of necrosis and apoptosis}

To establish whether the observed effects on inflammatory parameters were perhaps caused by modulation of cell necrosis or apoptosis, LDH levels in the supernatant and annexin- $V$ binding on the cells were quantified (Fig. 6). LDH in the supernatant of control cells amounted to $22.5 \pm 1.1 \mathrm{mU} / \mathrm{ml}$ and $\mathrm{did}$ not change significantly in any group. Annexin-V binding was not altered by $\mathrm{H}_{2} \mathrm{O}_{2}$ either alone or in combination with TNF- $\alpha$ (Fig. 6). TNF- $\alpha$ concentration dependently increased annexin- $\mathrm{V}$-specific fluorescence from $4.1 \pm 0.2$ units (control) to $7.4 \pm 0.9$ at $300 \mathrm{ng} / \mathrm{ml}$ (Fig. 6).

\section{IKB and NFKB}

I $\mathrm{B}$ was consistently found in the cytoplasm of control HUVECs (defined as $100 \%$ ). Addition of $\mathrm{H}_{2} \mathrm{O}_{2}$ or TNF- $\alpha$ caused severe reductions in IкB levels ( $31 \pm 9 \%$ and $53 \pm 14 \%$, resp., Table 2$)$. A combination of both stimuli did not show any interference or augmentation. IкB was absent from all nucleus preparations, which suggests good separation quality (data not shown).The p65 subunit of $\mathrm{NF} \kappa \mathrm{B}$ was detected in the cytoplasm of resting cells and, to a much lower extent, in the nuclei. This basal presence of p65 in the nucleus (set at 100\%) was also to be seen in the immunohistochemical confocal images (Fig. 7A). Both $\mathrm{H}_{2} \mathrm{O}_{2}$ and TNF- $\alpha$, separately caused increases of nuclear $\mathrm{NF \kappa B}(190 \pm 52 \%$ and $253 \pm 115 \%$, resp., Table 2 and Figs. $7 A, B)$. However, the effect of TNF- $\alpha$ on translocation of NFKB was totally inhibited by pretreatment of cells with $\mathrm{H}_{2} \mathrm{O}_{2}$, as shown by Western blotting and confocal microscopy (Table 2 and Figs. 7A, B).
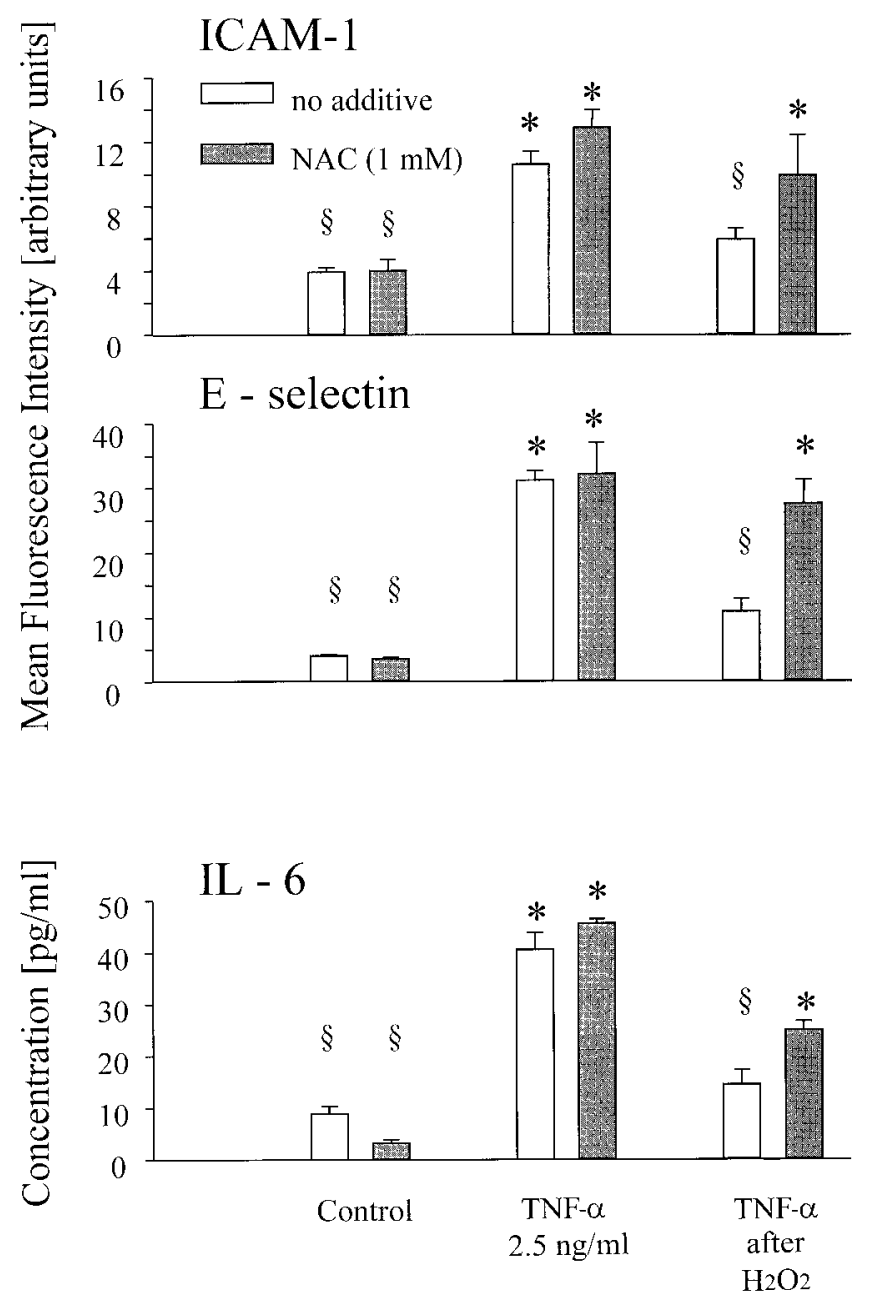

Figure 4. Effect of the intracellular radical scavenger NAC (N-acetylcysteine) on expression of ICAM-1 (upper panel) and E-selectin (middle panel), and on release of IL-6 (lower panel). $n=6$ cultures for all experimental groups. Means \pm SE; *significantly different from respective control, §significantly different vs. respective TNF- $\alpha$ group, $P \leq 0.05$. 
5 min after stimulation

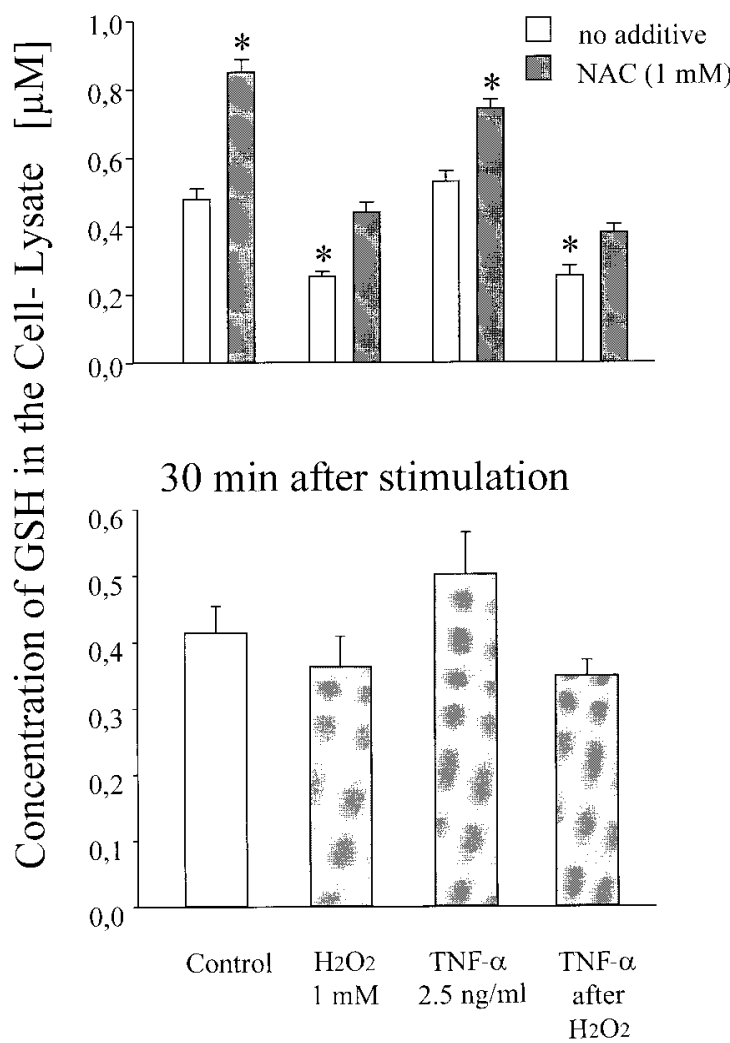

Figure 5. GSH levels in the lysates of HUVECs, 5 min (upper panel) and $30 \mathrm{~min}$ (lower panel) after initiation of different stimulation protocols. $n=6$ cultures for all conditions; means $\pm \mathrm{sE} ; *$ significantly different from control, $P \leq 0.05$.

\section{DISCUSSION}

Since its discovery in 1986 (3), the phenomenon of 'ischemic preconditioning' has aroused considerable interest. On the one hand, this is due to the fact that preconditioning is the most powerful tool known at present to reduce postischemic infarct size (21). On the other hand, the attention results from the growing clinical relevance and frequency of reperfusion scenarios. Knowledge of the underlying principles might help to design pharmacological interventions, keeping tissues at risk in a 'permanent state of preconditioning' (21). Accordingly, numerous studies have been performed to elucidate the mechanisms behind preconditioning, but the results have suggested nearly as many different mediators, including adenosine (5), acetylcholine (22), catecholamines (4), angiotensin II (23), bradykinin (24), nitric oxide (25), and reactive oxygen species (8). To make things even more complicated, the cellular targets of preconditioning seem to be heterogeneous. Though saline perfused isolated hearts or isolated cardiomyocytes can be preconditioned (15, 26), other reports suggest a microvascular component of preconditioning (27-29). This mainly concerns the reduction of postischemic inflammation or, more precisely, the mitigation of leukocyte adhesion in the
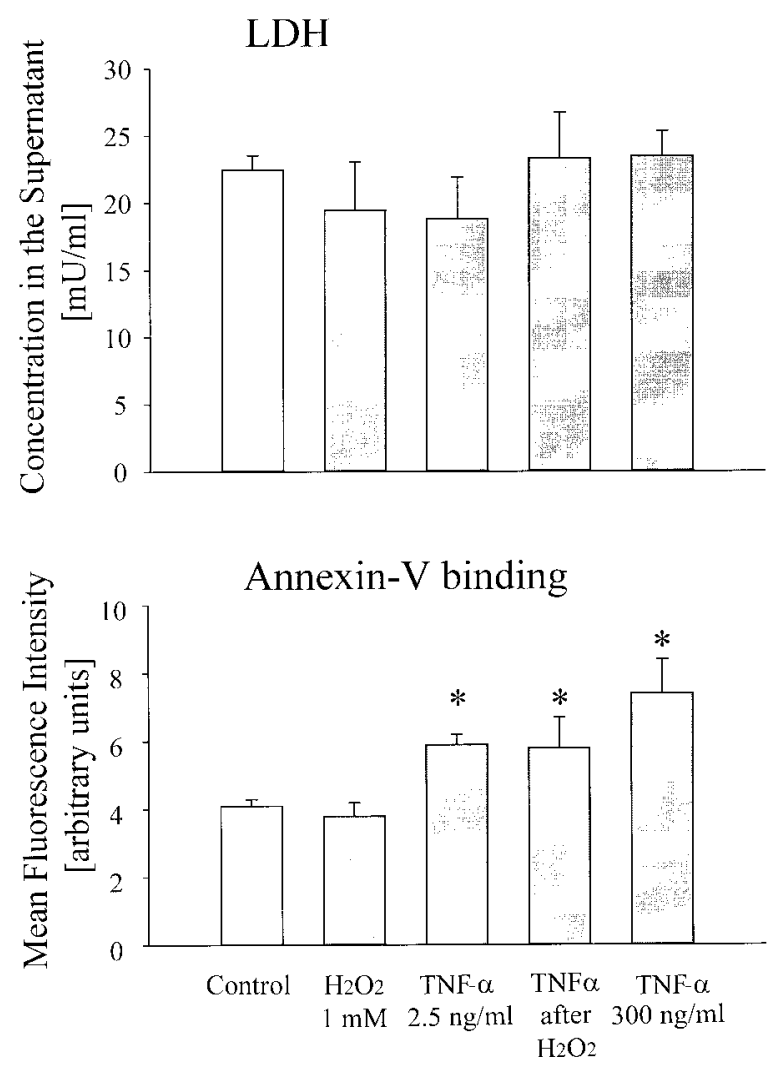

Figure 6. Upper panel: concentration of $\mathrm{LDH}$ in the supernatant of HUVECs incubated $4 \mathrm{~h}$ under various conditions. Lower panel: flow cytometric data on annexin- $\mathrm{V}$ binding to HUVECs after $4 \mathrm{~h}$. Controls: $n=7$ cultures, $\mathrm{H}_{2} \mathrm{O}_{2}: n=6$, TNF- $\alpha 2.5 \mathrm{ng} / \mathrm{ml}: n=9$, TNF- $\alpha(2.5 \mathrm{ng} / \mathrm{ml})$ after $\mathrm{H}_{2} \mathrm{O}_{2}: n=8$, TNF- $\alpha 300 \mathrm{ng} / \mathrm{ml}: n=6$. Means $\pm \mathrm{sE}$; *significantly different from controls, $P \leq 0.05$.

reperfused vascular bed that has been described after preconditioning $(10,30)$. Accordingly, it is tempting to speculate that the vascular endothelium, the interface between parenchymal tissue and blood cells, is involved in this phenomenon.

Oxidative stress has been shown to occur after preconditioning (13) and to be a mandatory factor of preconditioning at least in some models (14). Moreover, oxidative stress and changes in cellular redox status have turned out to be powerful modulators of intracellular signaling (19). For example, the expression of adhesion molecules and cytokines

TABLE 2. Densitometric evaluation of Western blots for $I \kappa B$ in the cytosolic fraction and for $N F \mathrm{k} B$ in the nuclear fraction of HUVECs lysed 30 min after intervention ${ }^{a}$

\begin{tabular}{|c|c|c|}
\hline $\begin{array}{l}\text { Experimental } \\
\text { condition }\end{array}$ & IкB in the cytoplasm & $\begin{array}{c}\text { NFкB in the nuclear } \\
\text { fraction }\end{array}$ \\
\hline Control & $100 \%$ & $100 \% \mathrm{~s}$ \\
\hline $\mathrm{H}_{2} \mathrm{O}_{2}(1 \mathrm{mM}, 5 \mathrm{~min})$ & $31 \pm 9 \% *$ & $190 \pm 52 \% *$ \\
\hline $\mathrm{TNF} \alpha(2.5 \mathrm{ng} / \mathrm{ml})$ & $53 \pm 14 \% *$ & $253 \pm 115 \% *$ \\
\hline $\mathrm{TNF} \alpha$ after $\mathrm{H}_{2} \mathrm{O}_{2}$ & $47 \pm 13 \% *$ & $113 \pm 75 \%^{\S}$ \\
\hline
\end{tabular}

${ }^{a} n=3$ for all conditions; * significant vs. control, ${ }^{\$}$ significantly different vs. TNF $\alpha, P \leq 0.05$, means \pm sD. 
A

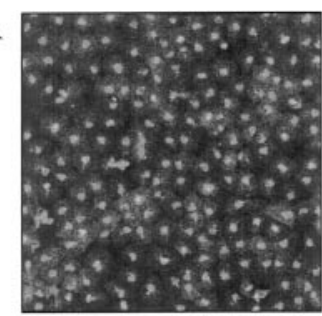

Control

B

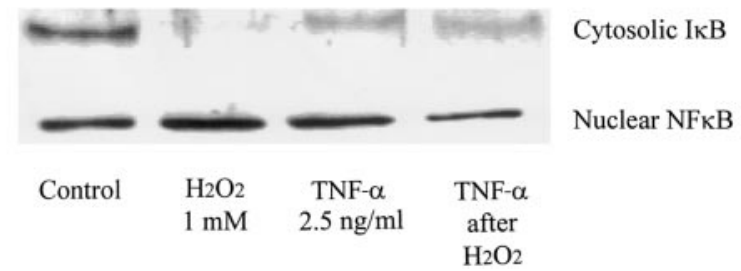

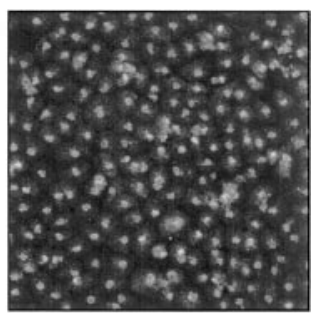

TNF- $\alpha$

after

$\mathrm{H}_{2} \mathrm{O}_{2}$
Figure 7. A) Immunofluorescent staining for the p65 subunit of NFкB. HUVECs were fixed in formalin $30 \mathrm{~min}$ after stimulation, permeabilized with Triton X-100, and stained with a p65 monoclonal antibody. Cells were inspected on a confocal microscope after incubation with an FITClabeled secondary antibody. B) Representative Western blots for the expression of

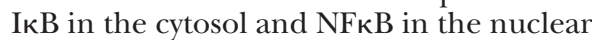
extract of HUVECs after different stimulation protocols. Quantitative densitometric evaluation is shown in Table 2. by endothelial cells is demonstrably regulated by changes in intracellular redox status (16). Since leukocyte recruitment at the site of reperfusion is caused by exactly these endothelial factors, we endeavored to establish whether oxidative stress might elicit a kind of anti-inflammatory 'endothelial preconditioning'.

To this end, we subjected HUVECs to $5 \mathrm{~min}$ incubation with $\mathrm{H}_{2} \mathrm{O}_{2}$, a reagent that has turned out to be a reproducible and easily controllable tool for generating reversible intracellular redox stress (31). TNF- $\alpha$ was used as a subsequent inflammatory stimulus because this cytokine has been shown by us (12) and others (11) to be released during postischemic reperfusion and to be a key mediator or reperfusion injury. The inflammatory parameters we measured were chosen in order to cover the whole cascade of leukocyte adhesion to the vessel wall and subsequent transmigration: P-selectin, which is stored in endothelial vesicles and can be rapidly transferred into the cell membrane on stimulation, enabling rapid recruitment of leukocytes and rolling along the vessel wall (32). E-selectin and ICAM-1 allow for sustained rolling at later time points and for firm adhesion, respectively. Finally, by chemotactically activating the leukocytes, IL-6 and IL-8 mediate the transition from rolling to firm adhesion (sticking), and cause transmigration (for a review, see ref 33). P-selectin has previously been shown to be rapidly expressed (within minutes) on the surface of HUVECs after treatment with $\mathrm{H}_{2} \mathrm{O}_{2}(31)$. Four hours later, P-selectin on HUVECs was still elevated (Table 1 ), but to an extent that does not necessarily involve de novo synthesis. The same was true for TNF- $\alpha$ or the combination of both stimuli (Table 1). The small extent of these effects might be due to the fact that the promoter region of human P-selectin lacks $\kappa B$ sites, necessary to cause the pronounced up-regula- tion of this adhesion molecule, e.g., in mice after stimulation with TNF- $\alpha$ (34). In contrast, as was to be expected, TNF- $\alpha$ caused dramatic increases of the expression of ICAM-1 and E-selectin (Fig. 2) and of the secretion of IL-6 and IL-8 (Fig. 3). Transient brief pretreatment with $\mathrm{H}_{2} \mathrm{O}_{2}$ inhibited all these inflammatory effects (Figs. 2 and 3), an action that could easily be interpreted as an endothelial preconditioning.

However, alternative explanations are also feasible. For instance, $\mathrm{H}_{2} \mathrm{O}_{2}$ can be a cytotoxic and proapoptotic stimulus, depending on concentration and incubation time. This is also true of TNF- $\alpha$. So, if most of the cells were to be killed or made apoptotic when both stimuli are combined in the preconditioning protocol, a reduction in protein synthesis by these cells would not be surprising. Such relatively nonspecific effects, however, were ruled out: neither LDH release (a sign of necrosis) nor annexin- $\mathrm{V}$ binding (a marker of apoptosis) was elevated beyond the extent observed after stimulation with TNF- $\alpha$ alone (Fig. 6). The sensitivity of the assay seems appropriate, as TNF- $\alpha$ did cause a concentration-dependent increase of annexin- $\mathrm{V}$ binding when given alone (Fig. 6).

It could further be argued that the relatively high concentration of $\mathrm{H}_{2} \mathrm{O}_{2}(1 \mathrm{mM})$ might have caused nonspecific extracellular alterations of cellular structures (e.g., the TNF- $\alpha$ receptor). Thus, to differentiate between possible extracellular oxidative effects and intracellular actions, the intracellular scavenger NAC, a precursor of GSH was used. NAC has been reported to prevent the redox mediated part of TNF- $\alpha$ action (19). In the present paper, however, we chose a concentration and incubation time for NAC that did not influence the effects of TNF- $\alpha$ on ICAM-1, E-selectin, or IL-6 (Fig. 4). Nevertheless, the increase in intracellular GSH levels to $\sim 200 \%$ of 
control levels found after treatment with NAC (Fig. 5) demonstrated that NAC had been taken up and metabolized by the endothelial cells. In contrast to the indifferent behavior of NAC toward $\mathrm{TNF} \alpha$, the protective effect of transient $\mathrm{H}_{2} \mathrm{O}_{2}$ application was nearly abolished by pretreatment with NAC (Fig. 4). This finding suggests that the protective effect of preconditioning with $\mathrm{H}_{2} \mathrm{O}_{2}$ is caused by changes of intracellular redox status.

Indeed, using GSH as a marker of intracellular redox stress showed that application of $\mathrm{H}_{2} \mathrm{O}_{2}$ reduced GSH levels to $\sim 50 \%$ of the control level (Fig. 5). This oxidative stress was transient, as it was detectable $5 \mathrm{~min}$ (but no longer $30 \mathrm{~min}$ ) after treatment. After pretreatment with NAC, GSH levels also decreased on incubation with $\mathrm{H}_{2} \mathrm{O}_{2}$, but they did not fall below the concentrations seen in untreated control cells (Fig. 5). Thus, these cells presumably did not experience critical oxidative stress in the course of the experiment. Accordingly, it may be concluded that the preconditioning effect in our model is caused by brief, nonlethal intracellular redox stress.

The classical protocols of ischemic preconditioning (short periods of ischemia immediately followed by a more severe ischemic insult) have revealed the transient nature of this phenomenon. Some years ago, however, an additional time course of myocardial protection had been detected: $\sim 24 \mathrm{~h}$ after the preconditioning process, there is a second phase of myocardial protection, which has been termed second window of protection (18). This kind of preconditioning has been ascribed to the delayed induction of cardioprotective mechanisms, like production of heat shock proteins (7). In this case, too, oxidative stress has been postulated as a key stimulus (26). However, when we extended our observations to a later time point, no influence on the inflammatory reactions of the endothelial cells was seen when $24 \mathrm{~h}$ lay between the applications of hydrogen peroxide and TNF- $\alpha$ (Figs. 2 and 3). The phenomenon of the second window of protection thus seems to be based on different mechanisms or it may not develop in HUVECs.

Most inflammatory parameters measured by us on HUVECs have been reported to be regulated by the transcription factor $\mathrm{NF} \kappa \mathrm{B}$. Upon stimulation, $\mathrm{NF} \kappa \mathrm{B}$ is translocated from the cytosol into the nucleus. This process is enabled by previous phosphorylation, ubiquitination, and proteasomal degradation of the inhibiting factor IкB. Since translocation of NFкB has also been shown to be redox sensitive (19) and to occur early after cardiac ischemia and reperfusion $(12,35)$, we investigated whether alterations of NFкB-mediated signaling might be causal for the reduced inflammatory reactions of HUVECs subsequent to preconditioning by oxidative stress. The translocation of $\mathrm{NF} \kappa \mathrm{B}$ into the nuclear fraction differed between treatments: whereas $\mathrm{H}_{2} \mathrm{O}_{2}$ and $\mathrm{TNF}-\alpha$ alone both caused translocation, sequential treatment (TNF- $\alpha$ after preconditioning with $\mathrm{H}_{2} \mathrm{O}_{2}$ ) was not additive and instead completely abolished the effects of the single stimuli (Figs. $7 A, B$ and Table $2)$. The fact that P-selectin, an adhesion molecule that is not regulated by $\mathrm{NF \kappa}_{\mathrm{B}} \mathrm{B}$ in human cells (34) - in contrast to the NFкB-dependent parameters ICAM-1, E-selectin, IL-6, and IL-8- did not respond to the preconditioning protocol (Table 1) further strengthens the hypothesis that $\mathrm{NF \kappa B}$ is a selective target for the inhibitory effects of brief oxidative stress.

The identical decrease of I $\mathrm{B}$ after treatment of HUVECs with either $\mathrm{H}_{2} \mathrm{O}_{2}$ alone, TNF- $\alpha$ alone, or TNF- $\alpha$ after $\mathrm{H}_{2} \mathrm{O}_{2}$ (Fig. $7 \mathrm{~B}$ and Table 2) suggests that the inhibition of translocation in the latter intervention group is not due to a different degree of phosphorylation of IкB (Table 2). Alternative explanations for the decreased level of nuclear NFкB could be an infringed transport of $\mathrm{NF} \kappa \mathrm{B}$ to and into the nucleus, altered permeability of nuclear pores for $\mathrm{NF \kappa B}$, or a lower binding affinity between NFкB and the DNA. To our knowledge, the first two mechanisms have not been validated for NFкB. In contrast, a reduction of $\mathrm{NF \kappa B}$ affinity toward its binding sites on DNA due to oxidative stress has been reported (36). However, in our model, no differences were observed in global oxidative stress (mirrored as GSH concentration) between treatment with $\mathrm{H}_{2} \mathrm{O}_{2}$ alone and with TNF- $\alpha$ after $\mathrm{H}_{2} \mathrm{O}_{2}$. This was the case both after 5 min or 30 min (Fig. 5), i.e., the time, when NFкB translocation was measured. Despite the absence of differences in global redox status between these two groups, it cannot be excluded that the redox state of specific thiols, which modulate TNF- $\alpha$ effects (17), might have been affected for this duration. A partial explanation of the anti-inflammatory actions of brief oxidative stress could be that $\mathrm{NF \kappa B}$ down-regulates its own expression via a negative feedback loop (37). Indeed, we have found that overall content of NFKB in HUVECs pretreated with $\mathrm{H}_{2} \mathrm{O}_{2}(1 \mathrm{mM}, 5 \mathrm{~min})$ was reduced to $\sim 60 \%$ of control cells $4 \mathrm{~h}$ after the treatment (data not shown). However, this change in NFкB expression cannot account for the rapid infringement of $\mathrm{NF} \kappa \mathrm{B}$ translocation $30 \mathrm{~min}$ after preconditioning.

The presence of NFкB in the nucleus is important but far from sufficient for the expression of ICAM-1, E-selectin, IL-6, and IL-8. Our data show, for instance, that redox stress in form of a brief pulse of $\mathrm{H}_{2} \mathrm{O}_{2}$ can cause translocation of $\mathrm{NF \kappa B}$ without subsequent up-regulation of adhesion molecules or cytokines (Table 2; Figs. 2 and 3). TNF- $\alpha$, in contrast, elicited $\mathrm{NF \kappa B}$ translocation and higher expression levels of the proinflammatory parameters, but with- 
out having induced oxidative stress. Thus, other (e.g., posttranscriptional) influences of the preconditioning protocol on inflammatory responses might occur in addition to the reduction of NFKB translocation. One feasible modulator of inflammatory reactions in this context might be nitric oxide, which on the one hand has been demonstrated to be involved in preconditioning in some models (25), and on the other has elicited protective actions during reperfusion (38).

In conclusion, we have shown for the first time that endothelial cells can be preconditioned by transient intracellular redox stress to reduce responsiveness to an inflammatory mediator. The finding that this phenomenon is related to infringed translocation of the transcription factor $\mathrm{NF \kappa B}$ may enable novel approaches directed toward alleviating reperfusion damage. Though the underlying mechanisms are not resolved, endothelial preconditioning may well account for the anti-adhesive effects of ischemic preconditioning $(10,30)$ and its protective role in the microvasculature $(27,28,29)$ in vivo. In a wider context, the intriguing finding that sequential stimuli can blunt each other with respect to translocation of NFKB might aid the further clarification of mechanisms involved in redox signaling.

The authors are indebted to Profs. E. Gerlach and U. Pohl and to Drs. H-Y. Sohn and T. Gloe for constructive discussion of the data. The technical assistance of Ms. D. Kiesl, E. Musiol, and V. Frei is gratefully acknowledged. The study was supported in part by the Friedrich-Baur-Foundation of the University of Munich.

\section{REFERENCES}

1. Hearse, D. J. (1977) Reperfusion of the ischemic myocardium. J. Mol. Cell. Cardiol. 69, 605-616

2. Ma, X.-L., Tsao, P. S., and Lefer, A. M. (1991) Antibody to CD-18 exerts endothelial and cardiac protective effects in myocardial ischemia and reperfusion. J. Clin. Invest. 88, 1237-1243

3. Murry, C. E., Jennings, R. B., and Reimer, K. A. (1986) Preconditioning with ischemia: a delay of lethal cell injury in ischemic myocardium. Circulation 74, 1124-1136

4. Banerjee, A., Locke Winter, C., Rogers, K. B., Mitchell, M. B., Brew, E. C., Cairns, C. B., Bensard, D. D., and Harken, A. H. (1993) Preconditioning against myocardial dysfunction after ischemia and reperfusion by an alpha 1-adrenergic mechanism. Circ. Res. 73, 656-670

5. Hoshida, S., Kuzuya, T., Nishida, M., Yamashita, N., Oe, H., Hori, M., Kamada, T., and Tada, M. (1994) Adenosine blockade during reperfusion reverses the infarct limiting effect in preconditioned canine hearts. Cardiovasc. Res. 28, 1083-1088

6. Schulz, R., Rose, J., and Heusch, G. (1994) Involvement of activation of ATP-dependent potassium channels in ischemic preconditioning in swine. Am. J. Physiol. 267, H1341-H1352

7. Marber, M. S., Latchman, D. S., Walker, J. M., and Yellon, D. M. (1993) Cardiac stress protein elevation $24 \mathrm{~h}$ after brief ischemia or heat stress is associated with resistance to myocardial infarction. Circulation 88, 1264-1272

8. Tritto, I., D'Andrea, D., Eramo, N., Scognamiglio, A., DeSimone, C., Violante, A., Esposito, A., Chiariello, M., and Ambrosio, G. (1997) Oxygen radicals can induce preconditioning in rabbit hearts. Circ. Res. 80, 743-748
9. Chatelain, P., Latour, J. G., Tran, D., de-Lorgeril, M., Dupras, G., and Bourassa, M. (1987) Neutrophil accumulation in experimental myocardial infarcts: relation with extent of injury and effect of reperfusion. Circulation 75, 1083-1090

10. Akimitsu, T., Gute, D. C., and Korthuis, R. J. (1996) Ischemic preconditioning attenuates postischemic leukocyte adhesion and emigration. Am. J. Physiol. 271, H2052-H2059

11. Squadrito, F., Altavilla, D., Zingarelli, B., Ioculano, M., Calapai, G., Campo, G. M., Miceli, A., and Caputi, A. P. (1993) Tumor necrosis factor involvement in myocardial ischaemia-reperfusion injury. Eur. J. Pharmacol. 237, 223-230

12. Kupatt, C., Habazettl, H., Goedecke, A., Wolf, D. A., Zahler, S., Boekstegers, P., Kelly, R. A., and Becker, B. F. (1999) Tumor necrosis factor- $\alpha$ contributes to ischemia- and reperfusioninduced endothelial activation in isolated hearts. Circ. Res. 84, $392-400$

13. Crestanello, J. A., Lingle, D. M., Kamelgard, J., Millili, J., and Whitman, G. J. R. (1996) Ischemic preconditioning decreases oxidative stress during reperfusion: a chemiluminescence study. J. Surg. Res. 65, 53-58

14. Baines, C. P., Goto, M., and Downey, J. M. (1997) Oxygen radicals released during ischemic preconditioning contribute to cardioprotection in the rabbit myocardium. J. Mol. Cell. Cardiol. 29, 207-216

15. Chen, W., Gabel, S., Steenbergen, C., and Murphy, E. (1995) A redox-based mechanism for cardioprotection induced by ischemic preconditioning in perfused rat heart. Circ. Res. 77, 424-429

16. Kokura, S., Wolf, R. E., Yoshikawa, T., Granger, D. N., and Aw, T. Y. (1999) Molecular mechanisms of neutrophil-endothelial cell adhesion induced by redox imbalance. Circ. Res. 84, 516524

17. Friedrichs, B., Müller, C., and Brigelius-Flohé, R. ( 1998) Inhibition of tumor necrosis factor- $\alpha$ - and interleukin-1-induced endothelial E-selectin expression by thiol-modifying agents. Arterioscler. Thromb. Vasc. Biol. 18, 1829-1837

18. Baxter, G. F., Marber, M. S., Patel, V. C., and Yellon, D. M. (1994) Adenosine receptor involvement in a delayed myocardial protection $24 \mathrm{~h}$ after ischemic preconditioning. Circulation 90, 2993-3000

19. Schreck, R., Rieber, P., and Baeuerle, P. A. (1991) Reactive oxygen intermediates as apparently widely used messengers in the activation of the NFKB transcription factor and HIV-1. EMBO J. 10, 2247-2258

20. Jaffe, E. A., Nachmann, R. L., Becker, C. G., and Minick, C. R. (1973) Culture of human endothelial cells derived from umbilical veins. Identification by morphologic and immunologic criteria. J. Clin. Invest. 52, 2745-2756

21. Yellon, D. M., Baxter, G. F., Garcia-Dorado, D., Heusch, G., and Sumeray, M. S. (1998) Ischaemic preconditioning: present position and future directions. Cardiovasc. Res. 37, 21-33

22. Yao, Z., and Gross, G. J. (1993) Acetylcholine mimics ischemic preconditioning via glibenclamide-sensitive mechanism in dogs. Am. J. Physiol. 264, H2221-H2225

23. Liu, Y., Tsuchida, A., Cohen, M. V., and Downey, J. M. (1995) Pretreatment with angiotensin II activates protein kinase $\mathrm{C}$ and limits myocardial infarction in isolated rabbit hearts. J. Mol. Cell. Cardiol. 27, 883-892

24. Goto, M., Liu, Y., Yang, X. M., Ardell, J. L., Cohen, M. V., and Downey, J. M. (1995) Role of bradykinin in protection of ischemic preconditioning in rabbit hearts. Circ. Res. 77, 611-621

25. Ferdinandy, P., Szilvassy, Z., Balogh, N., Csonka, C., Csont, T., Koltai, M., and Dux, L. (1996) Nitric oxide is involved in active preconditioning in isolated working rat hearts. Ann. N.Y. Acad. Sci. 793, 489-493

26. Zhou, X., Zhai, X., and Ashraf, M. (1996) Direct evidence that initial oxidative stress triggered by preconditioning contributes to second window of protection by endogenous antioxidant enzyme in myocytes. Circulation 93, 1177-1184

27. Jerome, S. N., Akimitsu, T., Gute, D. C., and Korthuis, R. J. (1995) Ischemic preconditioning attenuates capillary no-reflow induced by prolonged ischemia and reperfusion. Am. J. Physiol. 268, H2063-H2067

28. DeFily, D. V., and Chilian, W. M. (1993) Preconditioning protects coronary arteriolar endothelium from ischemia-reperfusion injury. Am. J. Physiol. 265, H700-H706 
29. Richard, V., Kaeffer, N., Tron, C., and Thuillez, C. (1994) Ischemic preconditioning protects against coronary endothelial dysfunction induced by ischemia and reperfusion. Circulation 89, 1254-1261

30. Kubes, P., Payne, D., and Ostrovsky, L. (1998) Preconditioning and adenosine in I/R-induced leukocyte-endothelial cell interactions. Am. J. Physiol. 274, H1230-H1238

31. Zahler, S., Kupatt, C., Möbert, J., Becker, B. F., and Gerlach, E. (1997) Effects of ACE-inhibition on redox status and expression of P-selectin of endothelial cells subjected to oxidative stress. $J$. Mol. Cell. Cardiol. 29, 2953-2960

32. Geng, J-G., Bevilacqua, M. P., Moore, K. L., McIntyre, T. M., Prescott, S. M., Kim, J. M., Bliss, G. A., Zimmerman, G. A., and McEver, R. P. (1990) Rapid neutrophil adhesion to activated endothelium by GMP-140. Nature (London) 343, 757-760

33. Jordan, J. E., Zhao, Z-Q., and Vinten-Johansen, J. (1999) The role of neutrophils in myocardial ischemia-reperfusion injury. Cardiovasc. Res. 43, 860-878

34. Pan, J., Xia, L., and McEver, R. P. (1998) Comparison of promoters for the murine and human P-selectin genes suggest species-specific and conserved mechanisms for transcriptional regulation in endothelial cells. J. Biol. Chem. 273, 10058-10067

35. Li, C., Browder, W., and Kao, R. L. (1999) Early activation of transcription factor $\mathrm{NF \kappa B}$ during ischemia in perfused rat heart. Am. J. Physiol. 276, H543-H552

36. Hayashi, T., Ueno, Y., and Okamoto, T. (1993) Oxidoreductive regulation of nuclear factor к B. J. Biol. Chem. 268, $11380-11388$

37. Lombardi, L., Ciana, P., Cappellini, C., Trecca, D., Guerrini, L., Migliazza, A., Maiolo, A. T., and Neri, A. (1995) Structural and functional characterization of the promoter regions of the NFкB2 gene. Nucleic Acids Res. 23, 2328-2336

38. Siegfried, M. R., Erhardt, J., Rider, T., Ma, X-L., and Lefer, A. M. (1992) Cardioprotection and attenuation of endothelial dysfunction by organic nitric oxide donors in myocardial ischemiareperfusion. J. Pharmacol. Exp. Ther. 260, 668-675

Received for publication June 8, 1999. Revised for publication October 22, 1999. 